ARTÍCULOS DE REVISIÓN 



\section{AVANCES EN EL TRATAMIENTO \\ DE AGUAS RESIDUALES ALIMENTICIAS \\ PARA LA PRODUCCIÓN DE BIOENERGÍA \\ EN CELDAS DE COMBUSTIBLE MICROBIANAS: \\ UNA REVISIÓN}

\section{ADVANCES IN THE TREATMENT OF FOOD WASTEWATER FOR THE PRODUCTION OF BIOENERGY IN MICROBIAL FUEL CELLS: A REVIEW}

\section{Ximena Duche Y. ${ }^{1}$, Raúl Bahamonde S. ${ }^{1 *}$}

Recibido: 01 de octubre 2020 / Aceptado: 18 de febrero 2021

DOI: 10.26807/ia.vi.193

Palabras claves: Agua residual alimenticia, celdas de combustible microbianas, contaminación ambiental, densidad de potencia. Keywords: Food wastewater, microbial fuel cells, environmental contamination, power density.

\section{RESUMEN}

La industria alimenticia a nivel mundial es una de las industrias con mayor impacto en el medio ambiente, por la alta cantidad de aguas residuales que

1 Universidad Central del Ecuador, Facultad de Ciencias Químicas Laboratorio de Energías Renovables y Catálisis, Ecuador, Quito. (txduche@uce.edu.ec; *correspondencia: rabahamonde@uce. edu.ec). 
desecha y por el alto contenido de materia orgánica en estas aguas. El uso de tecnologías que permitan tratar estas aguas y generar energía simultáneamente surge como una alternativa eficiente contra el problema de contaminación. Las celdas de combustible microbianas constituyen una alternativa eficaz para el tratamiento de aguas residuales industriales por su alta capacidad de remoción de materia orgánica y posterior generación de energía. Este documento revisa los últimos avances que se han realizado entorno al empleo de esta tecnología en el campo de la industria alimenticia. El principal objetivo de esta revisión es describir los componentes y arquitecturas utilizadas en las celdas de combustible microbianas y como estos inciden en la producción de electricidad y en la remoción eficiente de materia orgánica en aguas residuales de industria alimenticia. A su vez, se exploran los principales sustratos (tipo de agua residual) utilizados en la generación de mayor eficiencia energética. Se presentan los futuros retos y las perspectivas que permitan mejorar el uso de esta tecnología en el tratamiento de agua residual de la industria alimenticia y el aprovechamiento de la energía eléctrica que los microorganismos generan en el proceso de oxidación de materia orgánica.

\section{ABSTRACT}

The food industry is one of the most environment impact industries in the world due to the high amount of wastewater it discharges and the high content of organic matter in this water. The use of technologies to treat wastewater and generate energy simultaneously emerges as an efficient alternative to the problem of pollution. Microbial fuel cells are an effective alternative for the treatment of industrial food wastewater due to their high organic matter removal and subsequent energy generation. This work reviews the latest developments in the use of microbial fuel cells in the food industry. The main objective of this review is to describe the components and architectures used in microbial fuel cells and see how they affect the production of electricity and the efficient removal of organic matter in food industry wastewater. At the same time, the main food wastewater substrates (type of wastewater) used in the generation of higher energy efficiency are explored. In other words, it presents the future 
challenges and perspectives that will allow the improvement of the efficiency in the treatment of the food industry's wastewater and the use of the electrical energy that the microorganisms generate in the process of oxidation of organic matter.

\section{INTRODUCCIÓN}

En las últimas décadas, la industria alimenticia ha llegado ser el tercer usuario más grande de agua después del petróleo refinado, metales primarios e industria química (Tekerlekopoulou, Economou, Tatoulis, Akratos, \& Vayenas, 2020). Esto se debe por la alta demanda de alimentos a nivel mundial, lo cual convierte a esta industria en uno de los sectores productivos de mayor impacto sobre el medio ambiente, por su alto consumo de agua y por la inevotable producción de grandes volúmenes de aguas residuales (Abdallh, Abdelhalim, \& Abdelhalim, 2016).

Las aguas residuales derivadas de los diferentes sectores de la industria alimenticia presentan valores significativos de demanda química y biológica de oxígeno. Esto es causado por el alto contenido de materia orgánica, sólidos disueltos y suspendidos (incluidos aceites, grasas, grasas), nutrientes como nitrógeno (incluyendo amoníaco), fósforo y minerales (Tekerlekopoulou, Economou, Tatoulis, Akratos, \& Vayenas, 2020). Además, estos vertidos se caracterizan por tener un alto nivel de bio-degradabilidad y ausencia de productos químicos tóxicos, lo que los distinguen de las aguas residuales municipales e industriales (Emara, Abd El-Razek, \& Sayed Ahmed, 2017). Es así que el tratamiento de aguas residuales juega un papel importante para reducir la contaminación ambiental. Sin embargo, se estima que, del total de aguas residuales, solo un $3 \%$ de estos efluentes son tratados (Solano, 2011).

El emplear un método para el tratamiento de aguas residuales más amigable con el medio ambiente, a comparación de los métodos convencionales, ha permitido despertar el interés en el uso de las celdas de combustible microbianas. En la actualidad, el empleo de métodos con- 
vencionales para el tratamiento de aguas residuales de la industria alimenticia, resulta ser la opción más utilizada ya que esta tecnología emergente no es muy conocida por esta industria. A nivel global, son escasas las investigaciones que aportan información de tratamiento de aguas residuales provenientes de la industria alimenticia mediante el uso de celdas de combustible microbianas (MFC's, por sus siglas en inglés). Por estas razones, el presente trabajo aporta con información, avances de esta nueva tecnología en el tratamiento de aguas residuales alimenticias. Así, como el aporte para investigaciones futuras de la posible aplicación de esta nueva tecnología a escala industrial.

\section{METODOLOGÍA}

\section{Aguas residuales alimenticias y su impacto ambiental}

Actualmente, la alta demanda mundial de agua genera una gran preocupación por la sostenibilidad del medio ambiente. La industria cumple un papel importante en este tema, y se estima que la demanda mundial de agua para la producción industrial aumentará mucho más que en cualquier otro sector, alcanzando un incremento de aproximadamente $400 \%$ hasta el año 2050. La mayor parte de este aumento se producirá en las economías emergentes y en los países en desarrollo (WWAP, 2015). Con la continua demanda de agua por la in- dustria, la cantidad de aguas residuales producidas y su carga total de contaminantes aumentará progresivamente en todo el mundo. Sumado a esto, las cifras demuestran que más del $80 \%$ de las aguas residuales del mundo, y más del $95 \%$ en algunos países menos desarrollados, son desechadas al medio ambiente sin tratamiento previo (WWAP, 2017).

La industria alimenticia es considerada una de las industrias de mayor impacto sobre el medioambiente, debido a la cantidad de procesos productivos y los subproductos (biomasa residual) que genera (Restrepo, 2012). Para todos estos procesos se deben utilizar grandes cantidades de 
agua de buena calidad, empleada en los procesos de lavado, limpieza y desinfección; actividades que hacen de esta industria una de las de mayor generación de aguas residuales con alta carga de contaminantes orgánicos (Seijas, 2010).

Dentro de los residuos orgánicos de estos vertidos están grasas, proteínas, sales, sólidos suspendidos y sólidos disueltos, siendo los responsables de la alta demanda química de oxígeno (DQO, por sus siglas en inglés) y la alta demanda bioquímica de oxígeno (DBO, por sus siglas en inglés) (Solano, 2011). Estas altas concentraciones de DQO y DBO favorecen el fenómeno de eutrofización, proceso en el cual el exceso de nutrientes provoca el crecimiento en abundancia de algas que consumen una elevada cantidad de oxígeno disuelto y aportan materia orgánica en abundancia (iAgua, 2018), reduciendo la probabilidad de vida acuática y la muerte por asfixia de la fauna de estos ecosistemas (Centro de Producción más Limpia, 2017). Sumado a esto, las aguas residuales de las industrias de lácteos, azucareras, frutas, verduras, almidones, carnes, entre otras, favorecen la for- mación de bio-películas difíciles de eliminar debido a que presentan contaminantes biológicos, como las bacterias (Pariente, 2017).

\section{Celdas de Combustible Microbianas (MFCs)}

Las MFCs, son dispositivos que utilizan bacterias como catalizadores para oxidar materia orgánica e inorgánica y generar corriente (Logan et al., 2006). Las MFCs transforman un sustrato biodegradable directamente en electricidad, con lo que se liberan electrones, protones y $\mathrm{CO}_{2}$ (Serment et al., 2017). El sustrato que requieren las MFCs es la materia orgánica, la cual cumple el papel de combustible (Pant et al., 2010). Una celda de combustible microbiana, como se observa en la Figura 1, está compuesta por una cámara anódica y otra cámara catódica, en medio de las cuales se coloca una membrana de intercambio de protones. En cada una de las cámaras se encuentran electrodos, el ánodo en la cámara anaeróbica y el cátodo en la cámara aeróbica. En la cámara anaeróbica se suministra materia orgánica la cual es oxidada por acción de un microorganismo exoelectrogénico 
con producción de electrones y protones; los electrones producidos se transfieren a través de un circuito externo a la cámara catódica. Simultáneamente, los protones producidos en la cámara anódica migran hacia la cámara catódica a través de la membrana. En la cámara catódica los electrones, protones y oxígeno se combinan para producir agua (Revelo, Hurtado, \& Ruiz, 2013). Cada una de estas reacciones (ecuaciones 1-2), que se producen en cada etapa involucra una cantidad de energía que globalmente se cuantifica como la resistencia interna de la celda (Gatti, Quiñones, \& Milocco, 2016).

\section{ÁNODO}

Materia Orgánica $\stackrel{\text { microorganismos }}{\longrightarrow} \mathrm{CO}_{2}+\mathrm{H}^{+}+\mathrm{e}^{-}$

\section{CÁTODO}

$\mathrm{O}_{2}+4 \mathrm{H}^{+}+4 \mathrm{e}^{-} \rightarrow 2 \mathrm{H}_{2} \mathrm{O}$

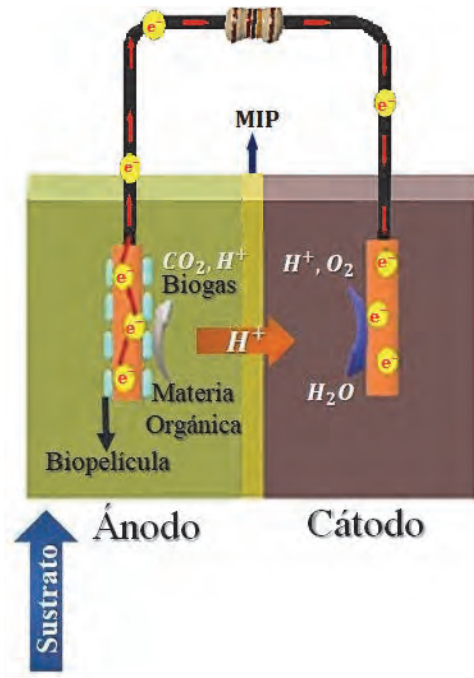

A)

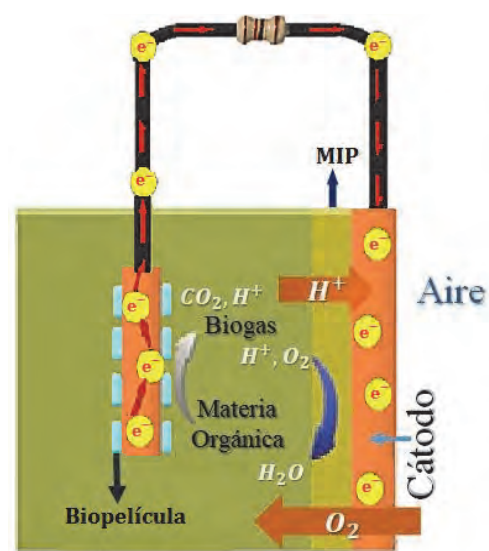

Ánodo

B)

Figura 1. Funcionamiento de MFCs, A) MFC de cámara doble B) MFC de una cámara 
Las reacciones que se llevan a cabo (ecuaciones 3-5), cuando se utiliza como sustrato acetato son las siguientes:

Ánodo: $\mathrm{CH}_{3} \mathrm{COO}^{-}+2 \mathrm{H}_{2} \mathrm{O} \rightarrow 2 \mathrm{CO}_{2}+7 \mathrm{H}^{+}+8 \mathrm{e}^{-} \quad \mathrm{E}^{\circ}=-0,29 \mathrm{~V}$

Cátodo: $\mathrm{O}_{2}+4 \mathrm{H}^{+}+4 \mathrm{e}^{-} \rightarrow 2 \mathrm{H}_{2} \mathrm{O}$

$\mathrm{E}^{\mathrm{O}^{\prime}}=+0,82 \mathrm{~V}$

${ }^{\circ} \Delta \mathrm{G}=-847,60 \mathrm{~kJ} / \mathrm{mol}$

fem $=+1,11 \mathrm{~V}$

Los potenciales estándares de reducción $\left(\mathrm{E}^{\circ}\right)$ ajustados, indican que la reacción redox que combina la reacción del ánodo y cátodo presenta un potencial de celda de $+1,11 \mathrm{~V}$, a $\mathrm{pH} 7$, por lo que la reacción es termodinámicamente favorable ( $\mathrm{Li}$ et al., 2018).

Las MFCs usualmente son fabricadas en vidrio y acrílico. Los electrodos que se utilizan son de diferentes materiales entre estos: platino, cobre y grafito. El separador consiste en una membrana que permite el paso de los protones de la cámara anódica hacia la cámara catódica e impide el paso de los electrones. Existen varios tipos de membranas, entre estas la más usada es la membrana de intercambio de cationes (MIC, por sus siglas en inglés) o también conocida como membrana de intercambio de protones (MIP, por sus siglas en inglés), membrana de intercambio de aniones, membrana bipolar, membrana de microfiltración, membrana de ultrafil- tración, fibra de vidrio, membranas porosas, entre otras (Revelo, Hurtado, \& Ruiz, 2013).

Además de la clásica MFC de doble cámara, se tiene la variante que consta solamente de una cámara (Figura 1B), donde se expone el cátodo directamente al aire, convirtiéndose en una celda más sencilla y de menor costo, debido al aumento de oxígeno involucrado en la reacción, mejorando el rendimiento de generación de electricidad. En este tipo de celda se puede colocar una MIC o simplemente prescindir de esta (Logan et al., 2006). 
Celdas de combustible microbianas como una alternativa en el tratamiento de aguas residuales

Existe una amplia gama de tecnologías y técnicas en la literatura para el tratamiento de aguas residuales de la industria alimenticia. Entre estos podemos mencionar los sistemas de tratamiento fisicoquímicos, biológicos (anaeróbico o aeróbico), humedales artificiales, métodos electroquímicos, biorreactores de membrana, procesos de oxidación avanzados o sistemas híbridos. Sin embargo, algunos se pueden aplicar a unidades pequeñas, mientras que otros solo se pueden aplicar a unidades más grandes, lo que constituye un problema para la industria alimenticia. A esto se suman los elevados costos que genera el empleo de estos métodos convencionales, debido a la cantidad de energía requerida y con ello el uso de combustibles fósiles para su generación (He et al., 2017). En Aguascalientes, México, se estima que entre 4 o 5 por ciento de la energía eléctrica se usa para el tratamiento de aguas residuales. Además, el manejo de estas aguas ha creado diversos problemas de contaminación ambiental, desde el incre- mento de la acidez del suelo y el agua hasta el calentamiento global, provocando que la calidad de vida disminuya (Aguasresiduales.in fo, 2017).

El uso de las MFCs hoy en día constituye una alternativa a esta problemática. Las celdas de combus- tible son aparatos electroquímicos capaces de operar continuamente, produciendo electricidad mientras son alimentadas con combustible y oxidante, transformando la energía química en eléctrica mediante reacciones de óxido-reducción en presencia de un catalizador, sin combustión y sin contaminar el aire ni el agua (Acuña \& Muñoz, 2001). Estos dispositivos utilizan bacterias como catalizadores para oxidar la materia orgánica e inorgánica, los electrones producidos por las bacterias de estos sustratos se transfieren al ánodo y fluyen hacia el cátodo unidos por un material conductor que contiene una resistencia (Logan et al., 2006). Este tipo de dispositivos electroquímicos eran utilizados por la NASA y algunos laboratorios, pero actualmente con la creciente necesidad de reducir la contaminación y la emisión de gases que favorecen el 
efecto invernadero ha resurgido el interés en emplear esta tecnología en todo el mundo, no solamente por su interés en generar energía sino por su capacidad de eliminar la carga contaminante de aguas residuales (Dominguez, 2002).

\section{RESULTADOS}

La observación de la generación de energía eléctrica por parte de las bacterias se debe a Potter en el año 1911, año en que surge una nueva tecnología para la obtención de energía limpia y renovable: las celdas de combustible microbianas. Los estudios realizados a partir de este descubrimiento fueron escasos, ya en el año 1960 las MFCs fueron un foco de interés y estudio por la comunidad científica (Logan, 2008), para posteriormente ser relegados hasta el año 2003, año en el cual se inicia con avances relevantes, como se muestra en la Tabla 1.

En esta Tabla 1 se reportan los primeros estudios con el uso de las MFCs que demostraron la obtención de energía con el empleo de sustratos simples como azúcares, lo que despertó el interés en experimentar con variedad de sustratos. Así, se experimentó con ácidos orgánicos, obteniéndose valores de energía ya más altos en comparación del uso de azúcares simples. Otros sustratos de interés fueron los alcoholes, como el etanol y el metanol. Los resultados mostraron, con el empleo de etanol, una mayor eficiencia de energía al usar un MFC de una cámara a comparación de un MFC de dos cámaras, y que al usar metanol no se obtenían resultados apreciables de energía. Al utilizar polisacáridos más complejos, como el almidón, quitina, celulosa, etc., se demostró que controlando el tamaño de partícula y el tipo de sustrato se pueden mantener resultados eficientes por un largo tiempo. Los resultados obtenidos con el uso de sustratos más complejos como aguas residuales sintéticas y reales demostraron que las MFCs eran efectivas para la generación de energía, además, se atribuyó la remoción de la materia orgánica, alcanzando nive- 


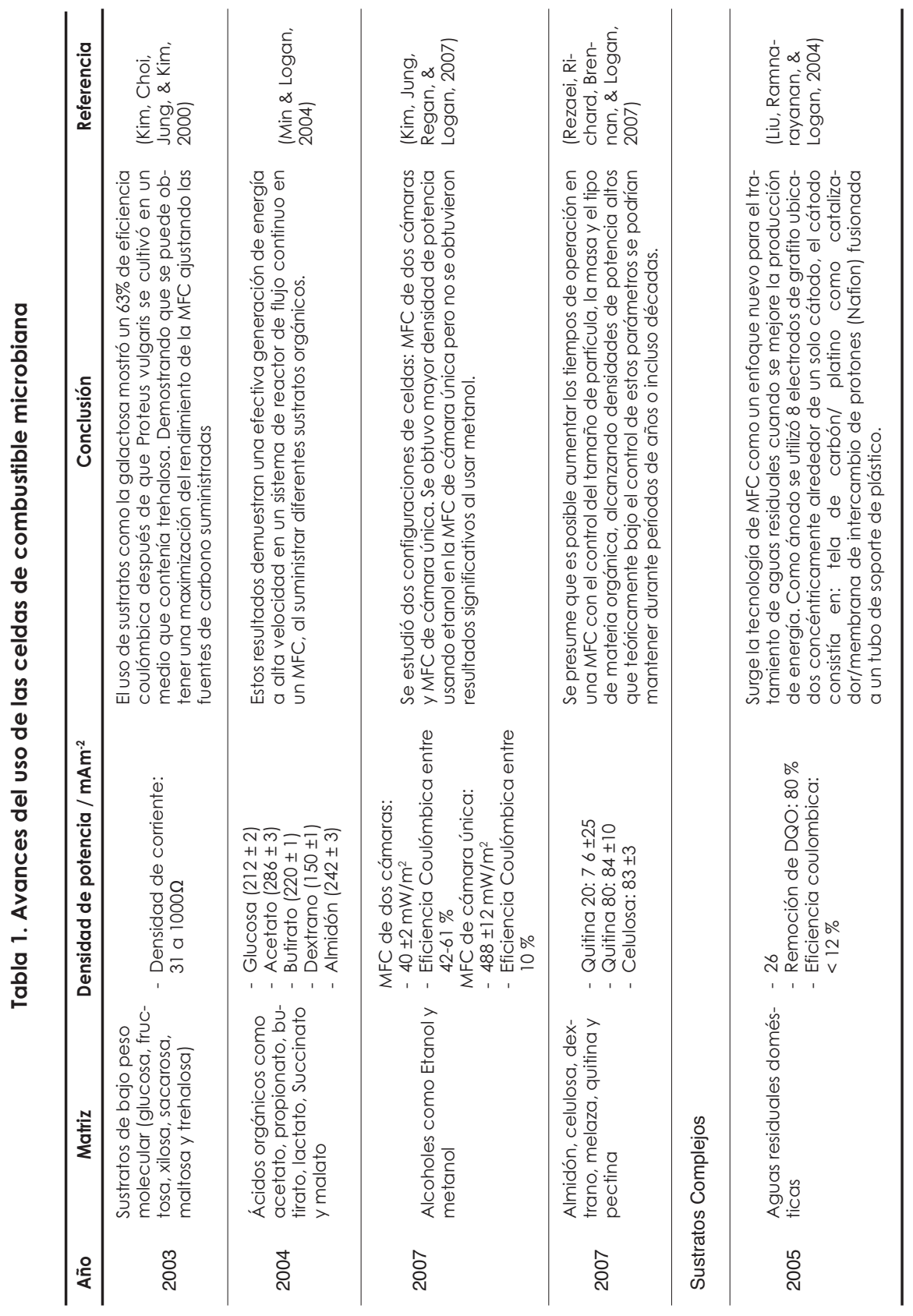


les de alrededor de $80 \%$ de remoción de DQO. Por lo que las MFCs se convirtieron una nueva tecnología para el tratamiento de aguas residuales, con un amplio campo de investigación, que permitiría lograr un mejor funcionamiento de la celda. Así, las MFCs tienen un gran potencial para el tratamiento de aguas residuales, por su alto contenido de materia orgánica, convirtiéndose en una tecnología idónea para el tratamiento de aguas residuales de la industria alimenticia.

Por otra parte, estudios posteriores han concluido que la cantidad de energía producida en una MFC puede ser afectada por diversos factores como: el diseño de configuración de la celda, tipo sustrato, tipo de inóculo y por las condiciones de operación. Es así que esta investigación recopila los avances realizados en el tratamiento de aguas residuales de la industria alimenticia con el uso de las MFCs. Para el mejor entendimiento de la presente revisión se ha clasificado la eficiencia de las celdas en función de los siguientes parámetros: tipo de sustrato, configuración de la celda y tipo de MFC empleada.

\section{Tipo de sustrato}

Para realizar un análisis más minucioso del efecto que tiene el tipo de sustrato en la eficiencia de la celda se muestra a continuación la Tabla 2. 


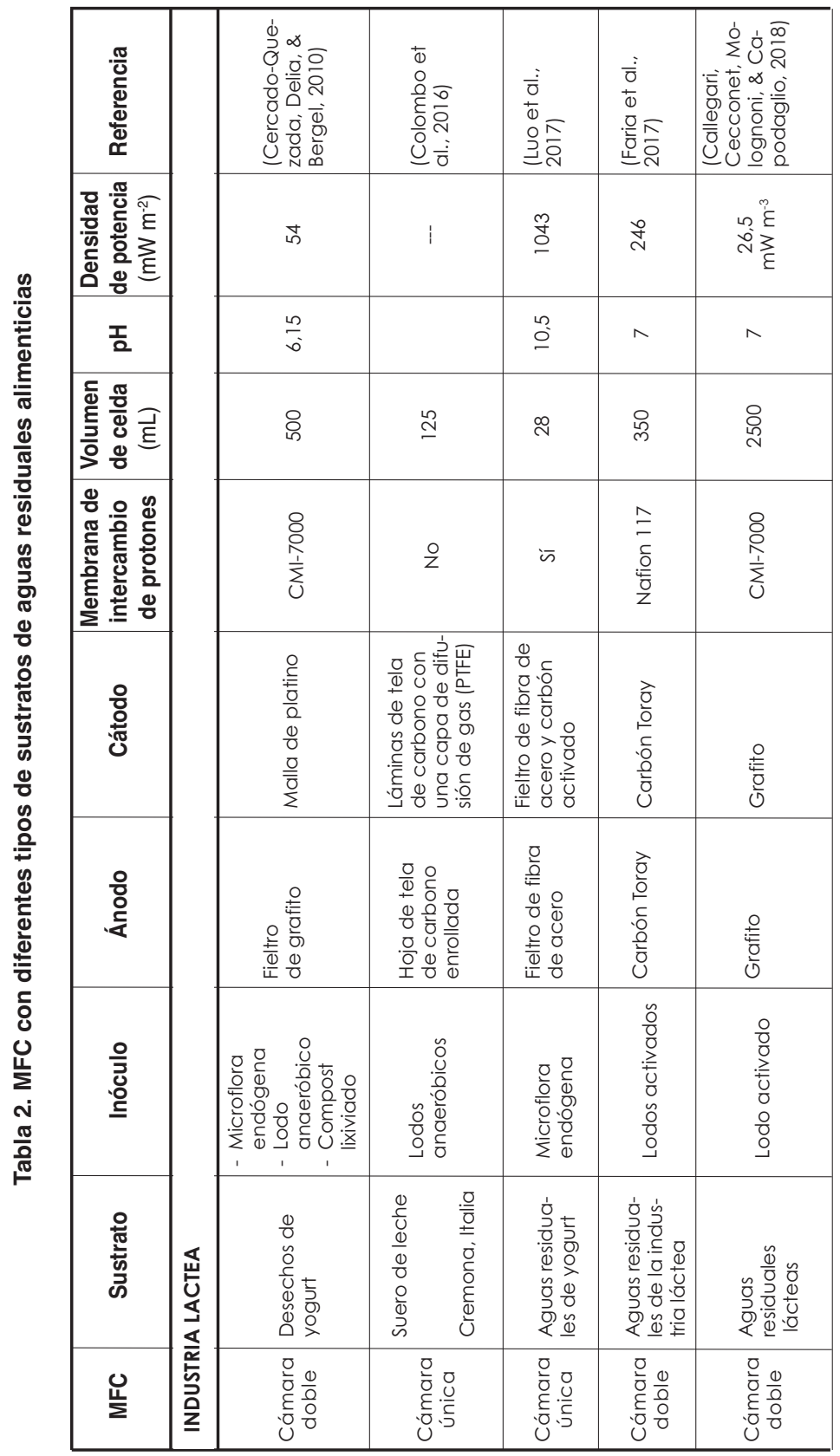




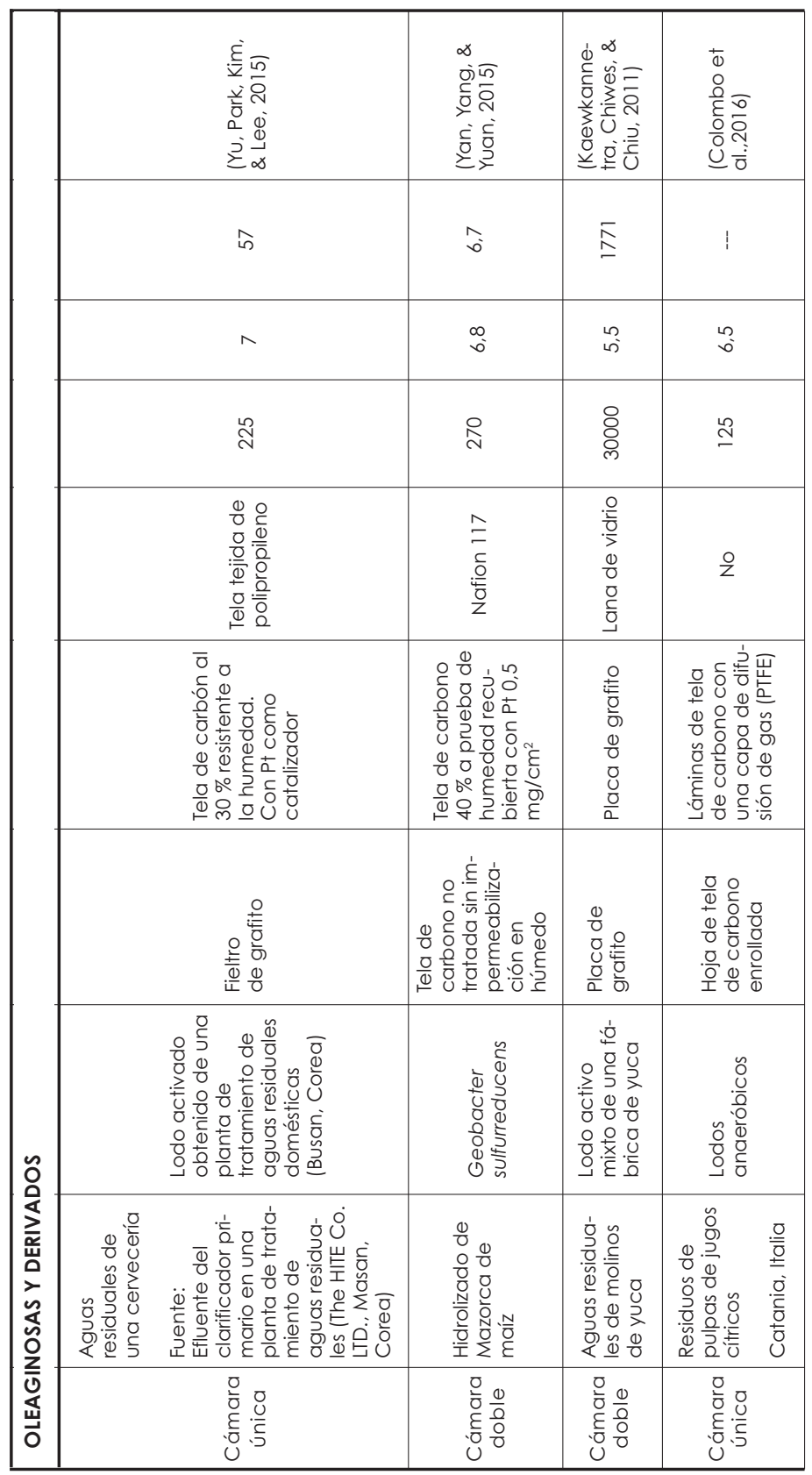




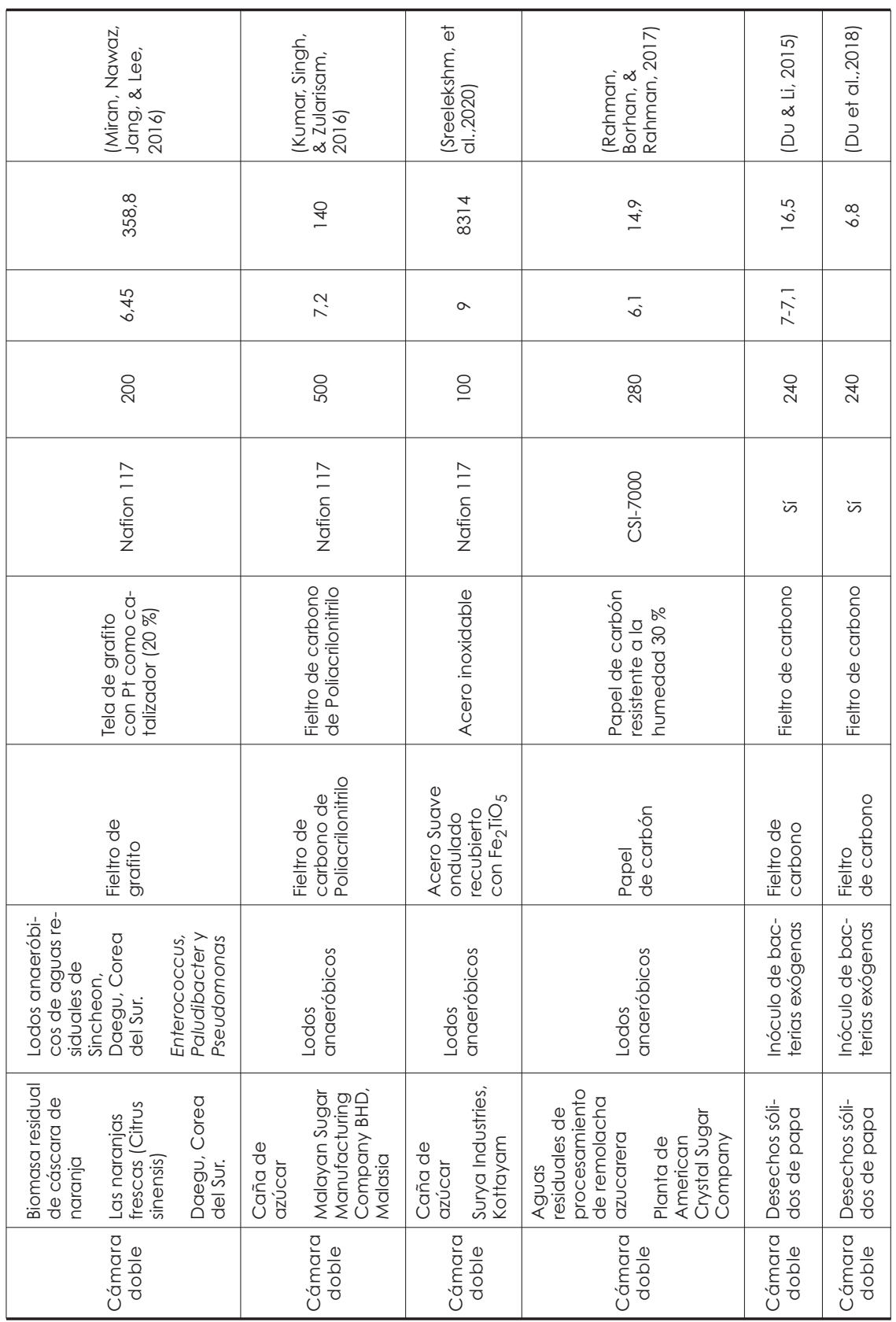


TRATAMIENTO DE AGUAS RESIDUALES ALIMENTICIAS

PARA LA PRODUCCIÓN DE BIOENERGÍA EN ECLDAS MICROBIANAS

Duche \& Bahamonde, 11-50

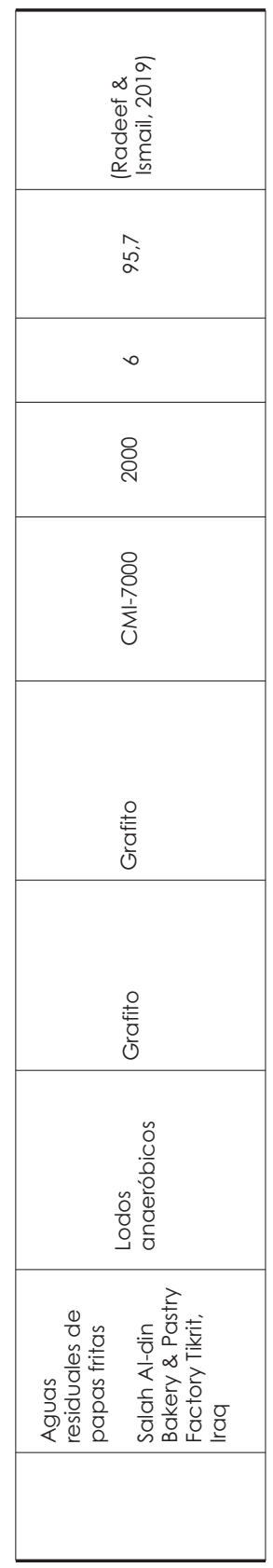




\begin{tabular}{|c|c|c|c|c|c|c|c|}
\hline & 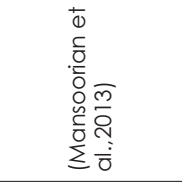 & 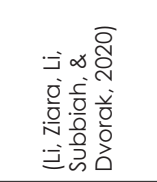 & & 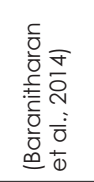 & 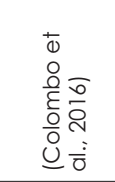 & 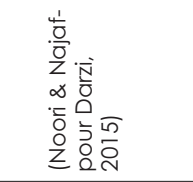 & 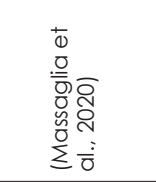 \\
\hline & సิ & 1 & & $\approx$ & 1 & \begin{tabular}{l}
$\infty$ \\
$\infty$ \\
$\infty$ \\
\multirow{N}{*}{$\xi$} \\
3
\end{tabular} & 1 \\
\hline & $\stackrel{n}{\stackrel{n}{\Lambda}}$ & $\wedge$ & & 我 & ?ִ & $\begin{array}{l}m \\
\infty \\
\text { in }\end{array}$ & $\wedge$ \\
\hline & 옴 & পু & & 号 & $\stackrel{2}{\underset{N}{2}}$ & ঃ & 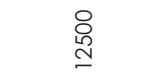 \\
\hline & 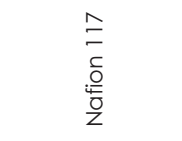 & 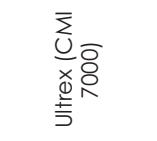 & & $\begin{array}{l}\text { D } \\
\bar{c} \\
\frac{0}{0} \\
\frac{O}{0} \\
z\end{array}$ & 을 & 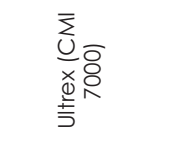 & ㅇ \\
\hline & $\begin{array}{l}\text { 은 } \\
\frac{1}{0} \\
0 \\
0 \\
0 \\
0 \\
.0 \\
0 \\
\end{array}$ & 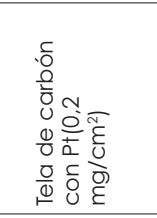 & & 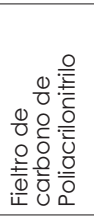 & 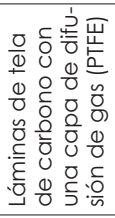 & 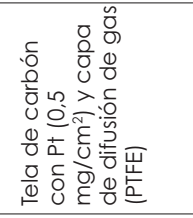 & 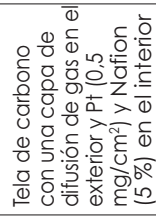 \\
\hline $\begin{array}{l}\text { 엉 } \\
\text { 뜽 }\end{array}$ & 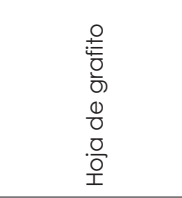 & 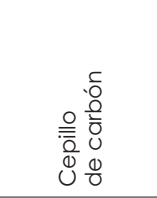 & & 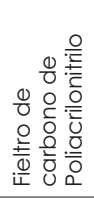 & 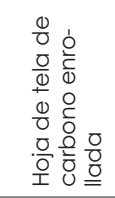 & 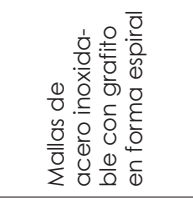 & 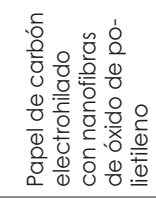 \\
\hline 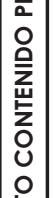 & 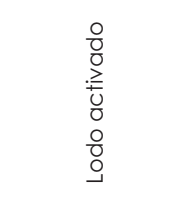 & 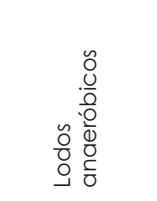 & & 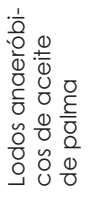 & 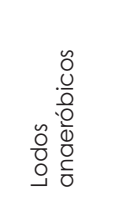 & 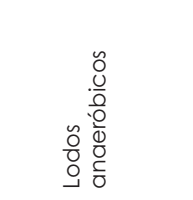 & 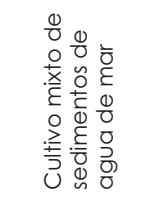 \\
\hline 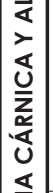 & 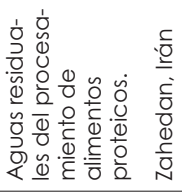 & 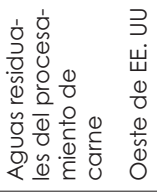 & 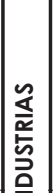 & 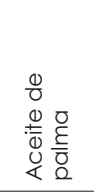 & 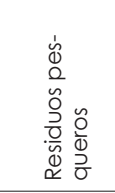 & 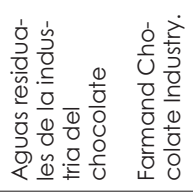 & $\overline{\frac{\Phi}{\Sigma}}$ \\
\hline $\begin{array}{l}\bar{\alpha} \\
\text { 号 } \\
\underline{\mathbf{n}}\end{array}$ & 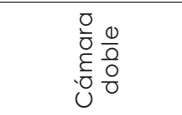 & $\begin{array}{l}\frac{\overline{0}}{\partial} \\
\frac{0}{\partial} \\
!\end{array}$ & $\begin{array}{l}z \\
\bar{n} \\
\frac{\alpha}{\alpha} \\
0\end{array} \mid$ & 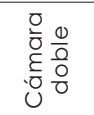 & 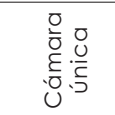 & $\begin{array}{l}\frac{\grave{0}}{2} \\
\frac{0}{\partial} \\
\models\end{array}$ & 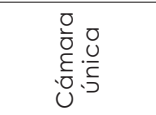 \\
\hline
\end{tabular}




\begin{tabular}{|c|c|c|c|c|c|c|}
\hline & 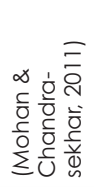 & 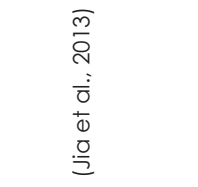 & 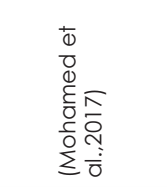 & 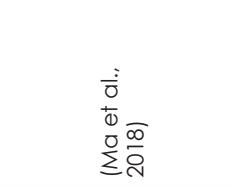 & 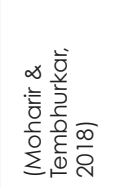 & 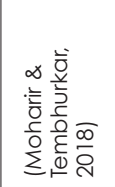 \\
\hline & 1 & సે & ৪ & 1 & $\begin{array}{l}\stackrel{m}{\alpha} \\
\stackrel{N}{N}\end{array}$ & 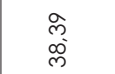 \\
\hline & $\wedge$ & $\wedge$ & 1 & $\wedge$ & $\begin{array}{l}\text { م. } \\
\text { m. } \\
0\end{array}$ & 1 \\
\hline & 유 & $\stackrel{\infty}{\sim}$ & চ & શิ & $\begin{array}{l}\stackrel{\circ}{n} \\
\stackrel{m}{ }\end{array}$ & 윰 \\
\hline & 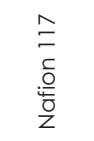 & i & is & 으 & 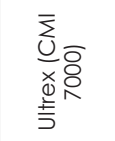 & 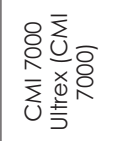 \\
\hline & $\begin{array}{l}\text { 온 } \\
i \frac{0}{0} \\
0 \\
0 \\
0 \\
0 \\
0 \\
0 \\
0 \\
\frac{0}{0}\end{array}$ & 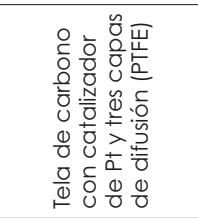 & 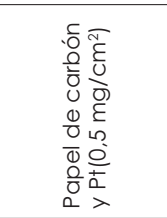 & 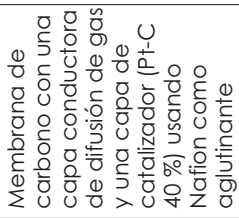 & 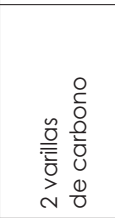 & 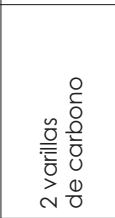 \\
\hline & 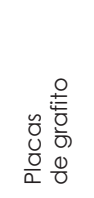 & 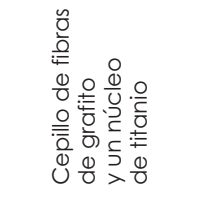 & 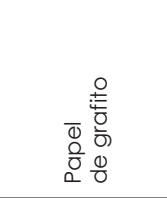 & 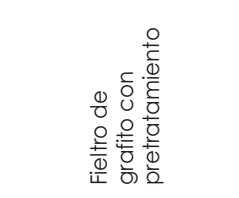 & 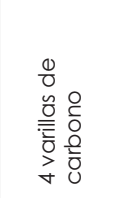 & 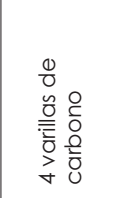 \\
\hline ก & 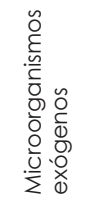 & 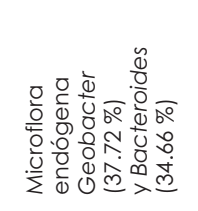 & 1 & 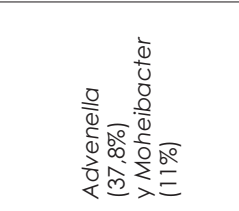 & 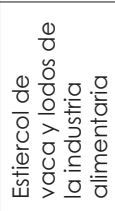 & 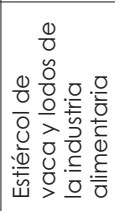 \\
\hline 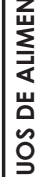 & 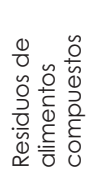 & 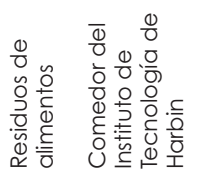 & 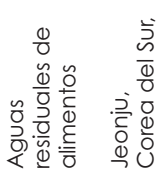 & 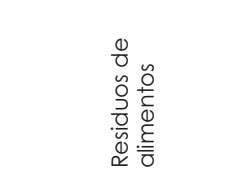 & 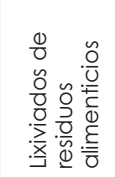 & 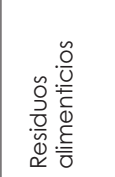 \\
\hline 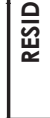 & 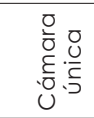 & 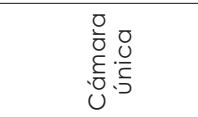 & 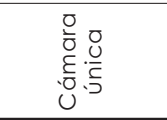 & 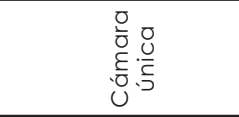 & 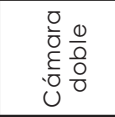 & 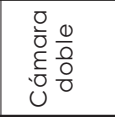 \\
\hline
\end{tabular}


InfoANALÍTICA NÚMERO ESPECIAL

Junio 2021

\begin{tabular}{|c|c|}
\hline 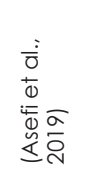 & 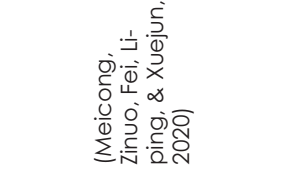 \\
\hline$\underset{\text { ন্ }}{ }$ & $\stackrel{\stackrel{\infty}{N}}{\sim}$ \\
\hline$\wedge$ & $\begin{array}{l}\infty \\
\stackrel{\infty}{\sim} \\
\end{array}$ \\
\hline$\stackrel{\text { ㄱ }}{ }$ & ৪্ল \\
\hline 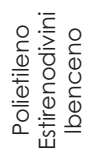 & $\begin{array}{l}\text { E } \\
\text { c } \\
i \frac{0}{0} \\
z \\
z\end{array}$ \\
\hline 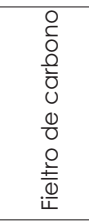 & 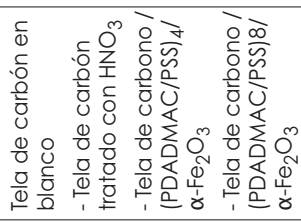 \\
\hline $\begin{array}{ll}\frac{0}{0} & 0 \\
0 & 0 \\
0 & 0 \\
\frac{\underline{t}}{0} & 0 \\
\frac{0}{0} & 0 \\
i \frac{1}{4} & 0\end{array}$ & 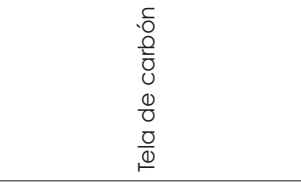 \\
\hline 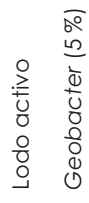 & 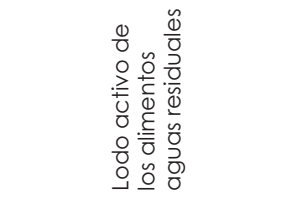 \\
\hline 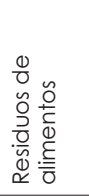 & 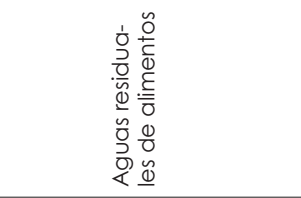 \\
\hline 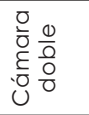 & 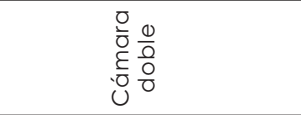 \\
\hline
\end{tabular}


TRATAMIENTO DE AGUAS RESIDUALES ALIMENTICIAS

PARA LA PRODUCCIÓN DE BIOENERGÍA EN ECLDAS MICROBIANAS

Duche \& Bahamonde, 11-50

\begin{tabular}{|c|c|c|c|c|c|c|c|c|}
\hline 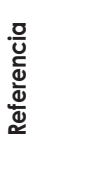 & 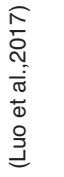 & 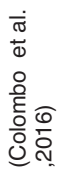 & & & 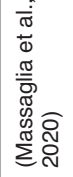 & 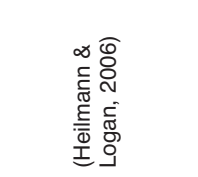 & & \\
\hline 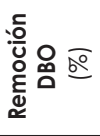 & & ! & i & & 1 & $\infty$ & 1 & 1 \\
\hline 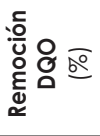 & $\hat{a}$ & $\begin{array}{l}a \\
\text { bे }\end{array}$ & 1 & $\begin{array}{l}\text { గ̂ } \\
\text { లై }\end{array}$ & 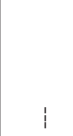 & 2 & $\mid$ & $\mid$ \\
\hline 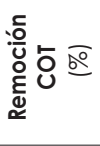 & & 1 & 1 & & 1 & 2 & 1 & i \\
\hline 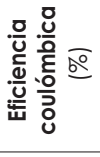 & $\stackrel{\sim}{N}$ & $\begin{array}{c}\text { S } \\
\text { i }\end{array}$ & $\stackrel{尺}{\curvearrowright}$ & $\frac{m}{m}$ & 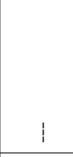 & 1 & 1 & 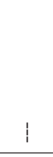 \\
\hline 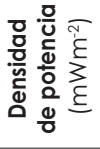 & $\stackrel{\text { Oִ }}{\triangle}$ & 1 & 1 & 1 & 1 & $\begin{array}{l}\overline{+1} \\
\stackrel{a}{g} \bar{\Xi}\end{array}$ & 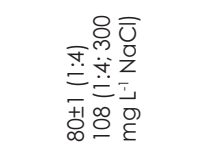 & $\stackrel{a}{p}$ \\
\hline 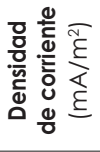 & : & ! & ! & ! & $\stackrel{N}{\tilde{N}}$ & $\stackrel{\circ}{\stackrel{\circ}{\circ}}$ & 只 & 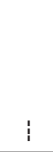 \\
\hline 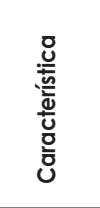 & & & & & & 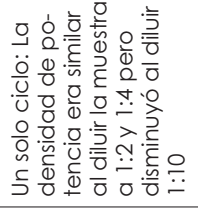 & 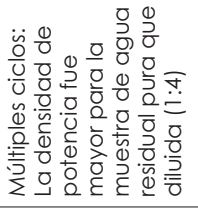 & 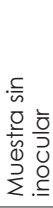 \\
\hline 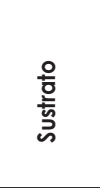 & 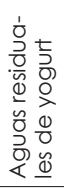 & $\begin{array}{l}\frac{0}{0} \\
\frac{0}{0} \\
\frac{0}{0} \\
0 \\
0 \\
\frac{0}{0} \\
\stackrel{0}{0}\end{array}$ & 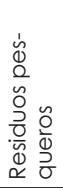 & 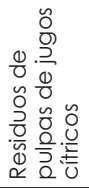 & $\overline{\frac{\Phi}{\Sigma}}$ & 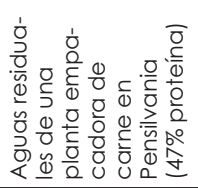 & & \\
\hline $\begin{array}{l}\stackrel{0}{0} \\
\text { 을 } \\
\text { : }\end{array}$ & \multicolumn{8}{|c|}{ 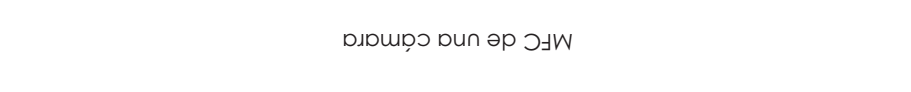 } \\
\hline
\end{tabular}




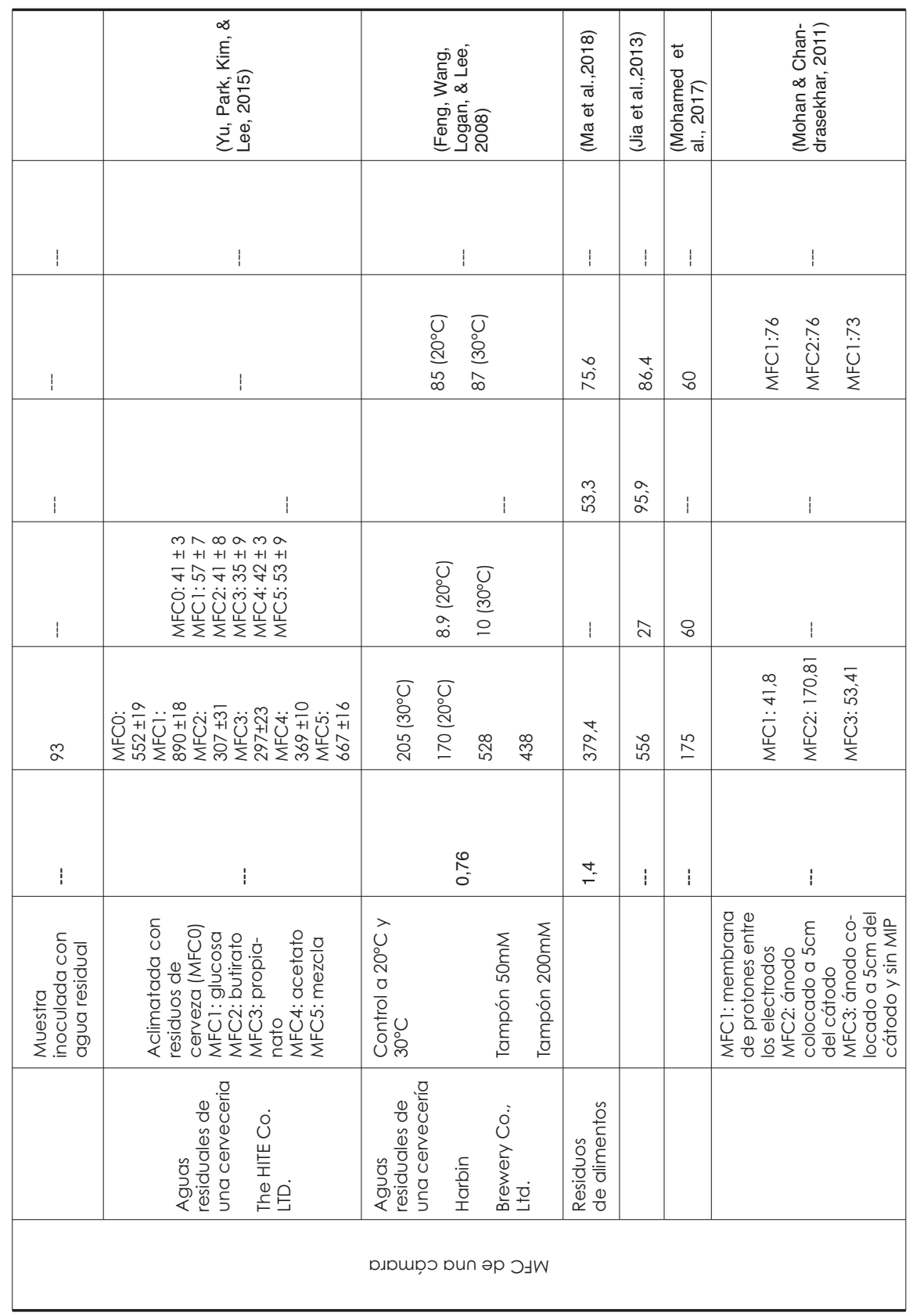


TRATAMIENTO DE AGUAS RESIDUALES ALIMENTICIAS

PARA LA PRODUCCIÓN DE BIOENERGÍA EN ECLDAS MICROBIANAS

Duche \& Bahamonde, $11-50$

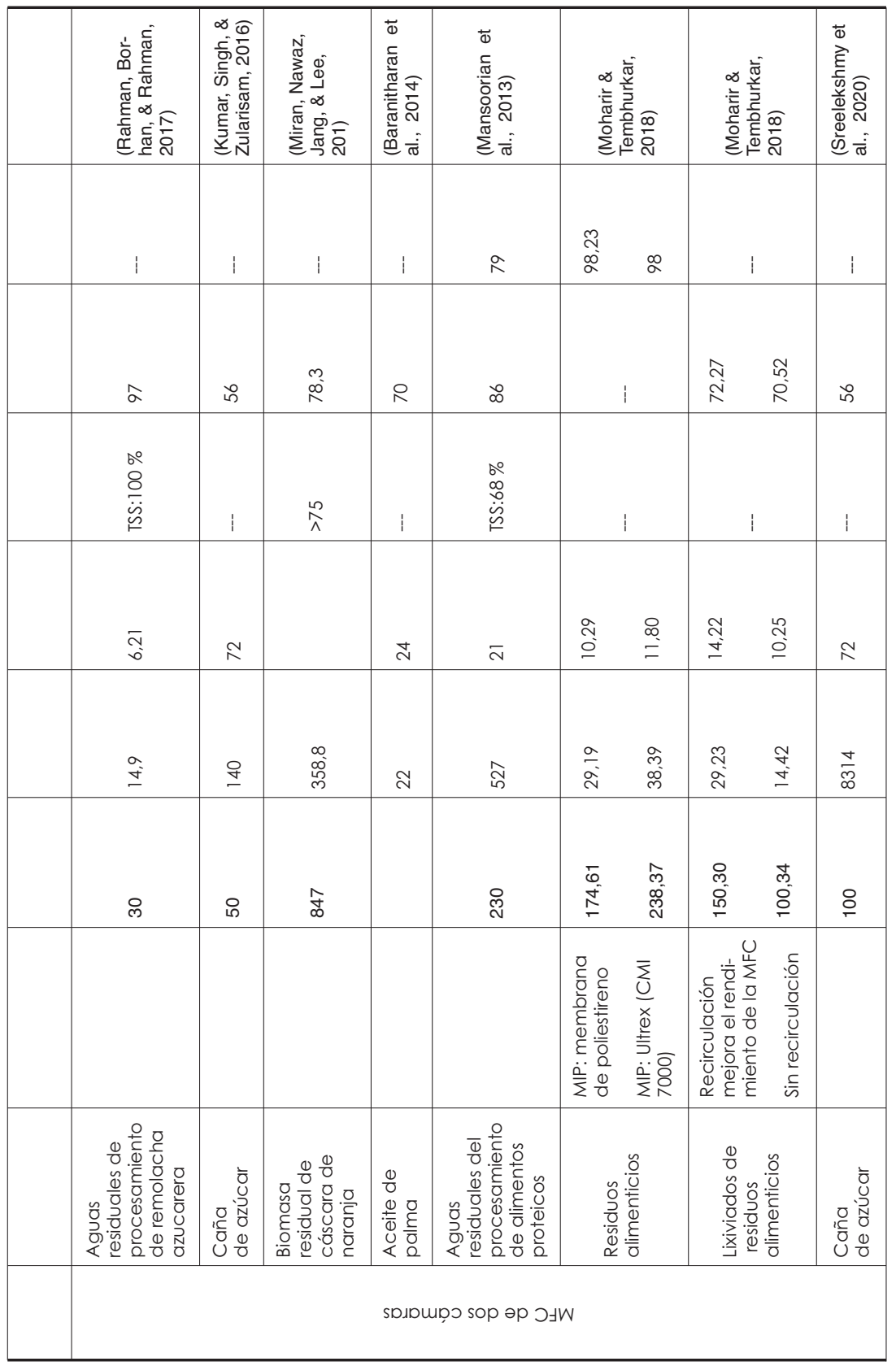


InfOANALÍTICA NÚMERO ESPECIAL

Junio 2021

\begin{tabular}{|c|c|c|c|c|}
\hline 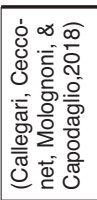 & 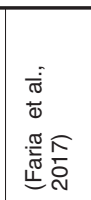 & 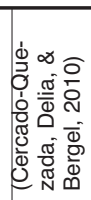 & 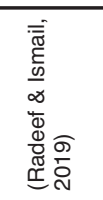 & 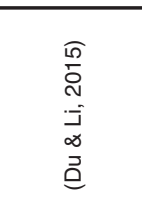 \\
\hline ! & 1 & 1 & 1 & 1 \\
\hline 9 & ஜి & 1 & 2 & 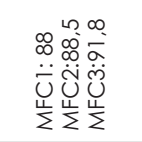 \\
\hline 1 & 亲 & 1 & 1 & 1 \\
\hline$\stackrel{\sim}{\sim}$ & $\stackrel{\text { I }}{\text { N }}$ & - & $\stackrel{a}{a}$ & 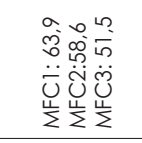 \\
\hline 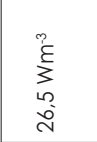 & 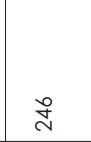 & in & బै & 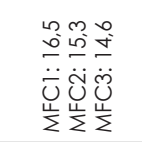 \\
\hline 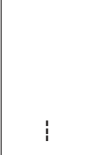 & $\underset{ه}{0}$ & $\underset{\widetilde{N}}{\tilde{N}}$ & $\begin{array}{l}n \\
\text { Ni } \\
\infty\end{array}$ & 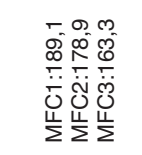 \\
\hline & & & & 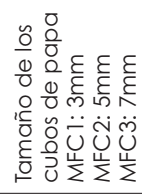 \\
\hline 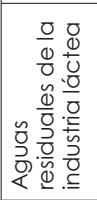 & 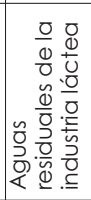 & 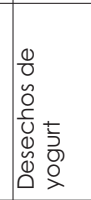 & 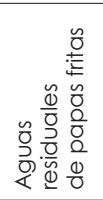 & 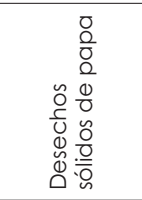 \\
\hline \multicolumn{5}{|c|}{ 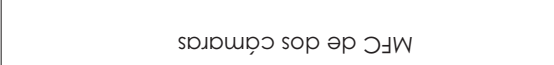 } \\
\hline
\end{tabular}




\section{Tipos de MFCs}

El tipo de MFC que se emplea para el tratamiento de aguas residuales alimenticias puede afectar su rendimiento, como se observa en la Tabla 3.

Los resultados obtenidos muestran que las MFCs de una cámara funcionan mejor a comparación de las MFCs de dos cámaras. Sin embargo, una desventaja de las MFCs de una cámara es el impedimento en proporcionar un ambiente anaeróbico estricto, en el que la difusión de oxígeno puede afectar el crecimiento de bacterias exoelectrogénicas, provocando su muerte y migración al cátodo formando biopelículas (Min, Kim, Oh, Regan, \& Logan, 2005). Debido a esto, el uso de una capa difusora de gas en la superficie del cátodo disminuye la difusión de oxígeno. Por otra parte, el uso de celdas de combustible tubulares también muestra valores altos de energía como lo demuestran Noori \& Najafpour Darzi (2015), al obtener una densidad de potencia de 22898 $\mathrm{W} / \mathrm{m}^{3}$ a partir de aguas residuales de la industria del chocolate.

\section{DISCUSIÓN}

Las aguas residuales de la industria alimenticia se caracterizan por el alto contenido de materia orgánica que poseen, por lo tanto, el tipo de vertido empleado como sustrato en la cámara anódica de las MFCs es un parámetro importante para predecir el funcionamiento de la celda, según Zhao (2017). Al emplear vertidos con alto contenido de residuos sólidos se produce mayor resistencia interna en la celda, lo que provoca la disminución de la densidad de potencia en comparación a cuando se utilizan sustratos de compuestos puros como la glucosa o acetato. Una alternativa a este problema fue descubierta por (Yu, Park, Kim, \& Lee, 2015), al aclimatar previamente a la celda con glucosa para tratar aguas residuales de cervecerías. Los resultados mostraron un aumento en la densidad de potencia y eficiencia coulómbica, de $552 \mathrm{~mW} / \mathrm{m}^{2}$ a 890 $\mathrm{mW} / \mathrm{m}^{2}$ y $41 \%$ a $57 \%$, respectivamente.

Por otra parte, el control en el ta- 
maño de partícula de los sólidos resulta también ser un parámetro importante para obtener densidades de potencia altas como lo predijeron Rezaei, Richard, Brennan, \& Logan (2007). Esto fue demostrado por Du \& Li (2015), ya que a medida que aumentaba el tamaño de los residuos sólidos de papa disminuía la densidad de corriente y potencia. Esto fue asociado a la hidrólisis de los residuos alimenticios previo al tratamiento, los cuales generan densidades de potencia altas; como lo demuestran Yan, Yang, \& Yuan (2015), al hidrolizar aguas residuales de maíz. Además, en el estudio realizado por Du (2018), se demostró que, al mezclar los residuos de alimentos de papa sólida cruda con papa hervida, se acelera la formación de los productos de hidrólisis en la etapa inicial de operación de la MFC, lo cual resultó en un aumento de la densidad de corriente máxima y acortó el tiempo necesario para alcanzar los niveles máximos de densidad de corriente. Por lo que la hidrólisis y la disminución del tamaño del residuo sólido serían una importante herramienta para mejorar el rendimiento de las MFCs.
Los estudios sobre MFC con sustratos complejos generalmente utilizan soluciones diluidas (Heilmann \& Logan, 2006). Las aguas residuales alimenticias, por ser complejas, generalmente se diluyen para evitar metabolismos planctónicos indeseables que pueden competir con la generación de electricidad catalizada por la biopelícula, además se diluyen para disminuir la suciedad en las superficies de los electrodos y las membranas (Cercado-Quezada, Delia, \& Bergel, 2010). Uno de los sustratos con alto contenido proteico son los residuos alimenticios de carne y productos lácteos, por lo que se prevé que el sustrato se debe diluir para una eficiente generación de electricidad. Sin embargo, según Heilmann \& Logan (2006), la densidad de potencia no se vio afectada por la dilución, al utilizar agua residual de carne. Actualmente Li, Ziara, Li, Subbiah, \& Dvorak (2020), se han centrado en este tipo de sustrato, obteniendo una densidad de corriente de $8,4 \mathrm{~A} / \mathrm{m}^{3}$ al utilizar una MFC tubular.

A pesar de que las aguas residuales de la industria láctea generalmente deben ser previamente diluidas (Luo 
et al., 2017) se ha mostrado que las aguas residuales derivadas de lácteos como el yogur, no diluidas, producen densidad de potencia elevada (1043 mW/m²) y una remoción de DQO del $97 \%$, lo que muestra que la dilución no es un factor crítico. Por otra parte, el pH mostró jugar un papel importante en el acondicionamiento del sustrato de yogur. La máxima densidad de potencia obtenida fue 12,9 veces mayor cuando el $\mathrm{pH}$ se ajustó a 8,5 en comparación con un $\mathrm{pH}$ de 6,15 (567 frente a 44 $\mathrm{mW} / \mathrm{m}^{2}$, respectivamente) (Luo et al., 2017). A su vez, los sustratos de frutas y verduras también se vieron afectados por el cambio de $\mathrm{pH}$ de los vertidos. En el estudio realizado por Colombo (2016) se muestra que las MFCs alimentadas con pulpas de cítricos comenzaron a funcionar solo cuando el pH se elevó a 6,5. Esto se debe a que el $\mathrm{pH}$ por debajo de 6,5 inhibe el crecimiento de bacterias exoelectrogénicas en el ánodo y por ende la biodegradación. El control de $\mathrm{pH}$ en el compartimento anódico generalmente se lleva a cabo añadiendo una solución buffer de fosfato para lograr $\mathrm{pH}$ superiores a 6,5. La adición del buffer provoca un aumento en la conductividad de la solución, lo que reduce resistencia óhmica y promueve el flujo de protones entre los electrodos, además regula el $\mathrm{pH}$ cerca de los electrodos (Cheng, Liu, \& Logan, 2006). Si bien el uso de esta solución buffer como regulador de $\mathrm{pH}$ del sustrato (anolito) y como catolito promueve la generación de energía, su empleo a escala industrial resultaría una desventaja en comparación de la energía producida, por el alto costo del buffer de fosfato. Debido a esto, el desarrollo de una alternativa que evite el uso de una solución buffer para controlar el $\mathrm{pH}$, pero que genere resultados eficientes de generación de energía, resultaría ser un avance prometedor en el uso de las MFCs.

Según Sreelekshmy (2020), es posible predecir todos estos parámetros (regulación de $\mathrm{pH}$ y dilución del sustrato), utilizando el modelado de Redes Neuronales Artificiales (ANN, por sus siglas en inglés), esto es útil para ajustar las condiciones óptimas para el funcionamiento adecuado de la MFC. Las condiciones ajustadas suministran más negatividad a las bacterias exoelectrogénicas en el sistema, lo que da como resultado una 
interacción eficiente entre las bacterias y el electrodo. Este modelo matemático fue aplicado en una MFC para el tratamiento de aguas residuales de la industria azucarera, lo que arrojó resultados prometedores para la industrialización de este proceso, con un costo de la inversión en la MFC de 199,15 USD. El valor de inversión por unidad de potencia producido fue de $0,48 \mathrm{USD} /\left(\mathrm{W} / \mathrm{m}^{2}\right)$ y el ingreso por unidad de energía producida de $8,63 \mathrm{USD} /\left(\mathrm{W} / \mathrm{m}^{2}\right)$, lo que resulta alrededor de 18 veces mayor que el de la inversión costo. Estos valores revelan la viabilidad y fiabilidad del empleo de MFC como un sistema eficiente para el tratamiento de aguas residuales (Sreelekshmy et al., 2020).

Los resultados mostrados en la Tabla 2 indican que las aguas residuales provenientes del molino de yuca, procesamiento de carne, elaboración de yogur, de la industria azucarera y de la industria del chocolate, han generado niveles altos de eficiencia en la obtención de energía. Sin embargo, las aguas residuales de la industria del chocolate presentaron los valores más altos de generación de energía, debido posible- mente a las grandes cantidades de azúcares y menores cantidades de residuos sólidos que la componen.

\section{Configuración de la celda}

\section{Modificación de electrodos}

La mayoría de los electrodos utilizados en MFCs para tratamiento de aguas residuales de la industria alimenticia han sido tela y fieltros de carbono como ánodos y cátodos; esto se debe a su alta actividad biocatalítica, lo que permite altos niveles de adhesión superficial de las bacterias exógenas. El uso de este material como ánodo mejoró la transferencia de electrones entre las bacterias y la superficie de este material, lo que resulta en una mayor generación de corriente y energía. Por otra parte, el recubrimiento de platino (Pt) como catalizador catódico presentó resultados más altos de densidades de potencia a comparación de un cátodo sin catalizador, debido a que el Pt es un excelente reductor de oxígeno (Chu et al., 2020), por lo que aprovecha el oxígeno del aire, acelerando las reacciones químicas en este compartimento. El catalizador común y único 
utilizado en los estudios fue Pt a concentraciones de $0,35 \mathrm{mg} / \mathrm{cm}^{2}$ y $0,5 \mathrm{mg} / \mathrm{cm}^{2}$. Por lo que el empleo de catalizador como el Pt resulta beneficioso para la obtención de energía. Es conocido que el Pt eleva los costos de elaboración de las MFCs, por lo que sustituirlo con materiales eficientes y económicos es una tarea para futuras investigaciones.

Otro factor importante de estudio es analizar el efecto de la distancia entre ánodo y cátodo. Mohan \& Chandrasekhar (2011) demostraron que la distancia entre los electrodos y la presencia de la membrana de intercambio de protones presentaban una influencia significativa en los rendimientos de energía. Encontraron que la mejor eficiencia se produce cuando el ánodo está relativamente separado del cátodo $(\sim 5 \mathrm{~cm})$ utilizando una MIP $\left(170,81 \mathrm{~mW} / \mathrm{m}^{2}\right)$.

En otro sentido, un factor importante a considerar es la modificación de electrodos, uno de los avances más actuales es la adición de polielectrolitos multicapas sobre el ánodo, lo que dio resultados muy prometedores. Según Meicong, Zinuo, Fei, Liping, \& Xuejun (2020), la adición de
4 capas dobles de polidimetil-dialil amonio (PDADMAC) + polisodio-estireno (PSS) y una capa de $\alpha-\mathrm{Fe}_{2} \mathrm{O}_{3}$ en el ánodo (tela de carbón) (PDADMAC/PSS) ${ }_{4} / \alpha-\mathrm{Fe}_{2} \mathrm{O}_{3}$ ) evidenciaba una densidad de potencia mayor. Esto se debe a que los polielectrolitos presentan propiedades similares a las de la membrana plasmática de las bacterias, imitando la capa de fosfolípidos de las células bacterianas (Amorosi et al.,2012). Además, poseen una gran biocompatibilidad, ya que la multicapa de polielectrolito hizo que la superficie del ánodo (tela de carbón) fuera más suave facilitando la adhesión de los flagelos bacterianos; promoviendo la transferencia de electrones en la superficie del ánodo por las bacterias presentes (Figura 2). Este resultado concuerda con varios estudios donde se ha demostrado que las proteínas redox de la membrana externa (OM) y los citocromos de tipo C (c-Cyt), desempeñaban un papel importante en la mediación de la transferencia de electrones de la célula a los óxidos de hierro (III) (Song, Zhao, Jiang, Zhang, \& Zhu, 2016). Además, las nanopartículas de $\alpha-\mathrm{Fe}_{2} \mathrm{O}_{3}$ mejoraron aún más la capacidad de transmisión electrónica de las membra- 
nas multicapa de polielectrolitos, debido a la relación de hierro (III) con las proteínas de la membrana microbiana, permitiendo la transferencia de electrones entre las bacterias y el ánodo (Meicong, Zinuo, Fei,
Liping, \& Xuejun, 2020). En ese sentido, la modificación del ánodo con polielectrolitos y nanopartículas de óxido de hierro generan resultados beneficiosos en la obtención de energía.

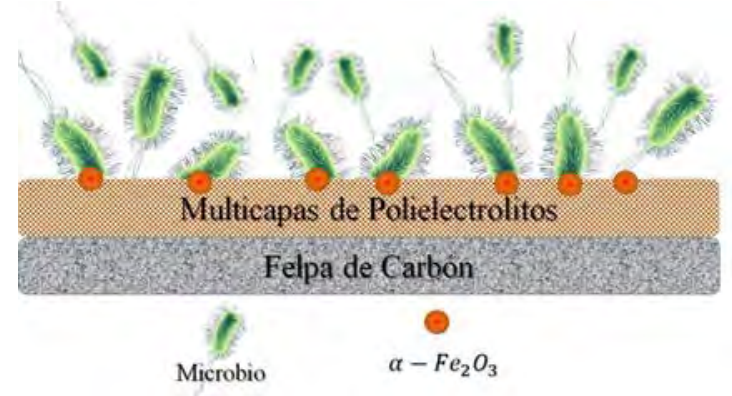

Figura 2. Mecanismo de transferencia de electrones de las bacterias al ánodo al utilizar polielectrolitos/ $\boldsymbol{\alpha}-\mathrm{Fe}_{2} \mathrm{O}_{3}$ (Meicong, Zinuo, Fei, Liping, \& Xuejun, 2020)

\section{Membrana de intercambio protó- nico (MIP)}

El uso de MIP, es utilizada por la mayoría de los estudios, demostrando eficiencias altas en comparación con las MFCs que no fueron configuradas con una MIP. Esto se debe a que la existencia de membrana de intercambio de protones puede mejorar la eficiencia coulómbica (CE) de las MFCs y propor- ciona un ambiente anaeróbico estricto para los microorganismos. Por lo que el uso de una MIP en las celdas de combustible microbianas permite maximizar la obtención de energía y remoción de materia orgánica en aguas residuales alimenticias.

Las membranas de intercambio protónico empleadas en los diferentes estudios se limitan a CMI-7000 y Nafion 117. El uso de estas membranas ha sido un empleo estándar en la MFCs, debido a que ofrecen una alta conductividad de protones por la presencia de grupos sulfonato fijados en una columna vertebral inerte (Oliot, Galier, Roux de Bal- 
mann, \& Bergel, 2016). Sin embargo, el uso de este tipo de membranas puede aumentar la resistencia interna, reduciendo así la generación de energía, lo cual puede ser perjudicial para la formación de biopelículas, además de disminuir la reproducibilidad de los resultados (Parot, Delia, \& Bergel, 2008).

Actualmente se conoce de varias membranas que proporcionan diferentes beneficios, entre ellas membranas de microfiltración, ultrafiltración y nanofiltración, pero ninguna de estas es aplicada en las MFCs para el tratamiento de aguas residuales alimenticias. Un buen candidato resulta ser la membrana de nanofiltración por el tamaño de sus poros muy pequeños; además, los mecanismos de retención de esta membrana se basan tanto en el tamaño como en la carga de las moléculas, por lo que los iones son retenidos mientras que el agua es transportada a través de la membrana, por esta razón se creería que estas membranas generan una alta resistencia a la transferencia de iones pero esta resistencia resultaría ser menor en comparación a las resistencias producidas por las membranas selecti- vas de iones, empleadas actualmente en las MFCs (Parot, Delia, \& Bergel, 2008). Por lo que se puede predecir que las membranas de nanofiltración resultan ser buenas candidatas para el tratamiento de aguas residuales por MFCs, reduciendo eficientemente el cruce de oxígeno y combustible entre los compartimentos. Además, es conocido que alrededor de las membranas de nanofiltración existe un amplio campo de estudio sobre la modificación superficial de estas, para hacerlas antiensuciantes y eficientes en el tratamiento de aguas residuales alimenticias (Bahamonde, Zhu, Gonza, Van der Bruggen, \& Luis, 2020), lo que las lleva a ser un candidato ideal para las MFCs.

\section{Tipo de inóculo}

En las MFCs un parámetro muy importante es el tipo de inóculo que se emplea para degradar la materia orgánica con el objetivo de producir energía. Las aguas residuales de la industria alimenticia resultan ser una gran fuente de minerales para el crecimiento bacteriano, ya que las bacterias tienden a degradar la materia orgánica soluble y biodegradable co- 
mo sustrato (proteínas y carbohidratos). Las bacterias anódicas pueden utilizar los aceptores de electrones presentes en las aguas residuales, como nitrato, Fe (III) soluble y sulfato (Fornero, Rosenbaum, \& Angenent, 2010).

Según Ma (2018), en su estudio empleando aguas residuales de alimentos, se encontró mediante secuenciación de alto rendimiento que las bacterias Advenella y Moheibacter se encontraban dentro de la mayor proporción entre todos los géneros bacterianos en el ánodo, en lugar de Geobacter como la literatura lo menciona. Esto se debe a que los residuos alimenticios contenían el gen de resistencia a antibióticos de tetraciclina, ya que en este estudio a los 6 días de cultivo la tasa de degradación de tetraciclinas alcanzó un valor significativo de 57,8\%. Demostrando así que Advenella es capaz de degradar las tetraciclinas a condiciones adecuadas $(\mathrm{pH} 7$ y 30 ${ }^{\circ} \mathrm{C}$ ). Este género de bacteria fue predominante no solamente en el ánodo sino también en el cátodo, demostrando su alta resistencia a las tetraciclinas presente en los desperdicios de alimentos (Lee et al.,
2007). Sin embargo, Geobacter es la propulsora de electricidad pero se obtuvo un efecto inhibitorio contra esta bacteria, presuntivamente por la presencia de Advenella y de ácido acético producto de la fermentación, lo cual en estudios posteriores debería ser cuestión de análisis. Una técnica para evitar que el tipo de inóculo sea un parámetro que afecte en la eficiencia de la MFC es cultivar las bacterias en acetato de sodio hasta alcanzar la estabilidad de la densidad de corriente para que las bacterias exoelectrogénicas se proliferen completamente en el ánodo. Este método permite que los resultados de rendimiento de la MFC no sean perjudicados por el tipo de inóculo empleado (Du et al., 2018).

Por otro lado, en aguas residuales con moderadas o bajas cantidades de tetraciclinas, la recopilación bibliográfica indica que las bacterias exoelectrogénicas predominantes son: Geobacter spp, Geobacter sulfurreducens, Clostridia butyricum, Enterococcus, Paludibacter y Pseudomonas. Además, los resultados obtenidos muestran que el uso de lodos activados y microflora endógena de las aguas residuales alimen- 
ticias como inóculos son eficientes para la generación de energía. Sin embargo, el uso de lodos activados predomina, esto se debe a la mayor cantidad de bacterias exoelectrogénicas presentes, necesarias para la generación de energía. Se debe tomar en cuenta que si la proporción de mezcla del lodo activado cultivado supera un cierto nivel, los productos de hidrólisis, probablemente pueden ser aprovechados por el mayor número de especies de bacterias heterotróficas ordinarias traídas por el lodo (Du et al., 2018).

\section{Tipos de MFCs}

Por otro lado, una recomendación que se puede destacar es analizar el efecto que puede producir el número de hélices del ánodo alrededor del cátodo y la modificación del espacio entre ellos (Figura 3B), ya que como lo describieron Noori \& Najafpour Darzi (2015), estas modificaciones podrían tener efectos positivos en el rendimiento de la MFC. Además, cabe señalar que en la fase operativa el impacto ambiental de la electricidad producida a partir de este tipo de MFC es mínimo en comparación con el consumo total de electricidad (Li, Ziara, Li, Subbiah, \& Dvorak, 2020). Con estos resultados se determina que las MFCs tubulares podrían ser una eficiente alternativa en el uso de MFCs.

Sin embargo, en estas últimas se han desarrollado diferentes estudios con el empleo de combustible de dos cámaras; esto se puede deber a que con el uso de la MFC se pueden es-

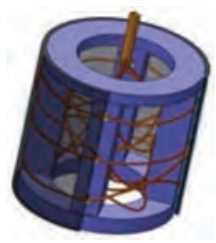

A)

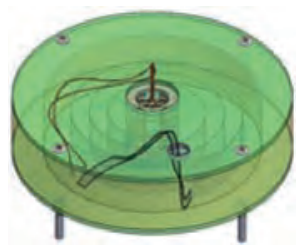

B)

Figura 3. Celdas tubulares A) Compartimento catódico, B) Esquema de la estructura de la celda circular con ánodo circular (Noori \& Najafpour Darzi, 2015) 
tudiar diferentes modificaciones por separado de los electrodos a diferencia del uso de celdas de una cámara. Los valores obtenidos demuestran el avance hacia el mejoramiento de las celdas de combustible microbianas con el uso de aguas residuales ali- menticias, permitiendo hasta la fecha obtener un valor de remoción del DQO de hasta el $97 \%$ y obtención de energía con densidad de potencia de hasta aproximadamente $8000 \mathrm{~mW} / \mathrm{m}^{2}$.

\section{CONCLUSIÓN}

Esta investigación bibliográfica recopiló información del empleo de las MFCs en el tratamiento de aguas residuales de la industria alimenticia, destacando los últimos avances que se han dado con el uso de esta tecnología. En este estudio, se muestra que las aguas residuales de la industria del chocolate son el mejor sustrato para obtener valores altos de energía $\left(22,898 \mathrm{~W} / \mathrm{m}^{2}\right)$. Aunque los estudios se orientan hacia el uso de MFCs de cámara única por sus bajos costos, el empleo de MFCs tubulares muestran valores más significativos en la generación de bioelectricidad. Además, un avance importante a destacar es la adición de multicapas de polielectrolitos $/ \alpha-\mathrm{Fe}_{2} \mathrm{O}_{3}$, por su similitud con la membrana plasmática de las bacterias. A su vez, el empleo del modelado de Redes Neuronales Artificiales resulta una importante herramienta que permite predecir y validar diferentes factores para lograr el mejor rendimiento de la celda y la obtención de energía (aprox.8000 $\mathrm{mW} / \mathrm{m}^{2}$ ) a partir de las aguas residuales alimenticias. Ante esto, se demuestra que el uso de las celdas de combustible microbianas para el tratamiento de aguas residuales alimenticias resulta una alternativa prometedora en la obtención de bioenergía y remoción de materia orgánica. 


\section{AGRADECIMIENTOS}

Los autores agradecen a la Universidad Central del Ecuador al apoyar financieramente este trabajo (Proyecto 061 Conv. 2019) y al equipo de trabajo del Laboratorio de Energías Renovables de la Facultad de Ciencias Químicas-UCE, que con su visión nos ha impulsado a contribuir con la presente investigación.

\section{LISTA DE REFERENCIAS}

Abdallh, M., Abdelhalim, W., \& Abdelhalim, H. (2016). Industrial wastewater treatment of food industry using best techniques. Int. J. Eng. Sci. Invent, 5(8), 15-28.

Acuña, F., \& Muñoz, V. (2001). Celdas de combustible. Una alternativa amigable con el medio ambiente para la generación de potencia y su impacto en el desarrollo sostenible de Colombia en el siglo XXI. Ingeniería \& Desarrollo, 10, 95.

Aguasresiduales.info. (02 de Marzo de 2017). Celdas de combustible microbianas para el tratamiento de aguas residuales. Obtenido de https://www.aguasresiduales. info/revista/noticias/celdas-de-combustible-microbianas-para-el-tratamiento-deaguas-residuales-qMMW0

Amorosi, C., Michel, M., Avérous, L., Toniazzo, V., Ruch, D., \& Ball, V. (2012). Plasma polymer films as an alternative to (PSS-PAH)n or (PSS-PDADMAC)n films to retain active enzymes in exponentially growing polyelectrolyte multilayers. Colloids and Surfaces B: Biointerfaces, 97, 124-131.

Asefi, B., Li, S.-L., Moreno, H. A., Sanchez-Torres, V., Hu, A., Li, J., \& Yu, C. (2019). Characterization of Electricity Production and Microbial Community of Food Waste-fed Microbial Fuel Cells. Process Safety and Environmental Protection, 125, 83-91. 
Bahamonde, R., Zhu, J., Gonza, I., Van der Bruggen, B., \& Luis, P. (2020). Effect of (TiO2: $\mathrm{ZnO}$ ) ratio on the anti-fouling properties of bio-inspired nanofiltration membranes. Separation and Purification Technology, 251, 117280.

Baranitharan, E., Khan, M. R., Prasad, D. M., Teo, W. F., Tan, G. Y., \& Jose, R. (2014). Effect of biofilm formation on the performance of microbial fuel cell for the treatment of palm oil mill effluent. Bioprocess and Biosystems Engineering, 38(1), $15-24$.

Callegari, A., Cecconet, D., Molognoni, D., \& Capodaglio, A. G. (2018). Sustainable processing of dairy wastewater: Long-term pilot application of a bio-electrochemical system. Journal of Cleaner Production, 189, 563-569.

Centro de Producción más Limpia. (17 de marzo de 2017). Manual de Buenas Prácticas Operativas de la Industria Láctea. . Obtenido de https://pml.org.ni/index.php/informese/publicaciones/file/205-bpoil-ma

Cercado-Quezada, B., Delia, M., \& Bergel, A. (2010). Testing various food-industry wastes for electricity production in microbial fuel cell. Bioresource Technology, $101(8), 2748-2754$.

Cheng, S., Liu, H., \& Logan, B. (2006). Increased performance of single chamber microbial fuel cells using an improved cathode structure. Electrochem Commun, 8(3), 489-494.

Chu, T., Xie, M., Yang, D., Ming, P., Li, B., \& Zhang, C. (2020). Highly active and durable carbon support Pt-rare earth catalyst for proton exchange membrane fuel cell. International Journal of Hydrogen Energy, 45 (51), 27291-27298.

Colombo, A., Schievano, A., Trasatti, S. P., Morrone, R., D'Antona, N., \& Cristiani, P. (2016). Signal trends of microbial fuel cells fed with different food-industry residues. International Journal of Hydrogen Energy, 42(3), 1841-1852.

Dominguez, J. J. (2002). Celdas de combustible (I). Anales de mecánica y electricidad, 2,14 .

Du, H., \& Li, F. (2015). Size effects of potato waste on its treatment by microbial fuel cell. Environmental Technology, 37(10), 305-1313. 
Du, H., Guo, J., Xu, Y., Wu, Y., Li, F., \& Wu, H. (2018). Enhancing microbial fuel cell (MFC) performance in treatment of solid potato waste by mixed feeding of boiled potato and waste activated sludge. Water Science and Technology, 78(5-6), 10541063.

Du, H., Guo, J., Xu, Y., Wu, Y., Li, F., \& Wu, H. (2018). Enhancing microbial fuel cell (MFC) performance in treatment of solid potato waste by mixed feeding of boiled potato and waste activated sludge. Water Science and Technology, 78(5-6), 10541063.

Emara, M., Abd El-Razek, A., \& SayedAhmed, A. (2017). Industrial food processing wastewater treatment by modified moving bed biofilm reactor (MBBR). International Journal of Scientific \& Engineering Research, 8(1), 929-934.

Faria, A., Gonçalves, L., Peixoto, J. M., Peixoto, L., Brito, A. G., \& Martins, G. (2017). Resources recovery in the dairy industry: bioelectricity production using a continuous microbial fuel cell. Journal of Cleaner Production, 140, 971-976.

Feng, Y., Wang, X., Logan, B., \& Lee, H. (2008). Brewery wastewater treatment using air-cathode microbial fuel cells. 75(8), 873-880.

Fornero, J., Rosenbaum, M., \& Angenent, L. (2010). Electric power generation from municipal, food, and animal wastewaters using microbial fuel cells. Electroanalysis, 22(7-8), 832-843.

Gatti, M., Quiñones, F., \& Milocco, R. (2016). Estudio de diferentes celdas de combustible microbianas para la generación de energía a partir de residuos orgánicos de efluentes líquidos. VI Congreso Internacional Sobre Gestión y Tratamiento Integral del Agua, 1,2. Córdoba.

He, L., Du, P., Chen, Y., Lu, H., Cheng, X., Chang, B., \& Wang, Z. (Mayo de 2017). Avances en celdas de combustible microbianas para el tratamiento de aguas residuales. Renewable and Sustainable Energy Reviews, 71, 388-403.

Heilmann, J., \& Logan, B. (2006). Production of Electricity from Proteins using a Microbial Fuel Cell. Water Environment Research, 78(5), 531-537. 
iAgua. (11 de abril de 2018). Eutrofización: Causas, consecuencias y soluciones. doi:https://www.iagua.es/noticias/sewervac-iberica/eutrofizacion-causas-consecuencias-y-soluciones

Jia, J., Tang, Y., Liu, B., Wu, D., Ren, N., \& Xing, D. (2013). Electricity generation from food wastes and microbial community structure in microbial fuel cells. Bioresource Technology, 144, 94-99.

Kaewkannetra, P., Chiwes, W., \& Chiu, T. Y. (2011). Treatment of cassava mill wastewater and production of electricity through microbial fuel cell technology. Fuel, 90(8), 2746-2750.

Kim, J., Jung, S., Regan, J., \& Logan, B. (2007). Electricity generation and microbial community analysis of alcohol powered microbial fuel cells. Bioresource Technology, 98(13), 2568-2577.

Kim, N., Choi, Y., Jung, S., \& Kim, S. (2000). Effect of initial carbon sources on the performance of microbial fuel cells containingProteus vulgaris. Biotechnology and Bioengineering, 70(1), 109-114.

Kumar, R., Singh, L., \& Zularisam, A. (2016). Bioelectricity generation and treatment of sugar mill effluent using a microbial fuel cell. Journal of Clean Energy Technologies, 4(4), 249-252.

Lee, J., Shin, S., Jang, H., Kim, Y., Lee, J., \& Kim, Y. (2007). Characterization of antibiotic resistance genes in representative organic solid wastes: food waste-recycling wastewater, manure, and sewage sludge. Sci. Total Environ., 579, 1692-1698.

Li, J., Ziara, R. M., Li, S., Subbiah, J., \& Dvorak, B. I. (2020). Understanding the sustainability niche of continuous flow tubular microbial fuel cells on beef packing wastewater treatment. Journal of Cleaner Production, 257.

Li, M., Zhou, M., Tian, X., Tan, C., McDaniel, C., Hassett, D., \& Gu, T. (2018). Microbial fuel cell (MFC) power performance improvement through. Biotechnology Advances, 36(4), 1317. 
Liu, H., Ramnarayanan, R., \& Logan, B. (2004). Production of electricity during wastewater treatment using a single chamber microbial fuel cell. Environmental Science \& Technology, 38(7), 2281-2285.

Logan, B. (2008). Microbial Fuel Cell. New Jersey: Wiley.

Logan, E., Hamelers, B., Rozendal, R., Schroder, U., Keller, J., Freguia, S., Aelterman, P., Verstraete, W., \& Rabaey, K. (2006). Microbial fuel cells: Methodology and technology. Environ. Sci. Technol., 40(17), 5181-5192.

Luo, H., Xu, G., Lu, Y., Liu, G., Zhang, R., Li, X., Zheng, X., \& Yu, M. (2017). Electricity generation in a microbial fuel cell using yogurt wastewater under alkaline conditions. RSC Advances, 7(52), 32826-32832.

Ma, H., Peng, C., Jia, Y., Wang, Q., Tu, M., \& Gao, M. (2018). Effect of fermentation stillage of food waste on bioelectricity production and microbial community structure in microbial fuel cells. Royal Society Open Science, 5.

Mansoorian, H. J., Mahvi, A. H., Jafari, A. J., Amin, M. M., Rajabizadeh, A., \& Khanjani, N. (2013). Bioelectricity generation using two chamber microbial fuel cell treating wastewater from food processing. Enzyme and Microbial Technology, 52(67), 352-35.

Massaglia, G., Frascella, F., Chiadò, A., Sacco, A., Marasso, S. L., Cocuzza, M., Pirri, C., \& Quaglio, M. (2020). Electrospun Nanofibers: from Food to Energy by Engineered Electrodes in Microbial Fuel Cells. Nanomaterials, 10(3), 523.

Meicong, W., Zinuo, W., Fei, H., Liping, F., \& Xuejun, Z. (2020). Polyelectrolytes/ - $\mathrm{Fe} 2 \mathrm{O} 3$ modification of carbon cloth anode for dealing with food wastewater in microbial fuel cell. Carbon Resources Conversion, 3, 76-81.

Min, B., \& Logan, B. (2004). Continuous Electricity Generation from Domestic Wastewater and Organic Substrates in a Flat Plate Microbial Fuel Cell. Environmental Science \& Technology, 38(21), 5809-5814.

Min, B., Kim, J., Oh, S., Regan, J., \& Logan, B. (2005). Electricity generation from swine wastewater using microbial fuel cells. Water Research, 39(20), 4961-4968. doi:10.1016 / j.watres.2005.09.039. 
Miran, W., Nawaz, M., Jang, J., \& Lee, D. S. (2016). Conversion of orange peel waste biomass to bioelectricity using a mediator-less microbial fuel cell . Science of The Total Environment, 547, 197-205.

Mohamed, H. O., Obaid, M., Sayed, E. T., Abdelkareem, M. A., Park, M., Liu, Y., Kim, H., \& Barakat, N. A. (2017). Graphite Sheets as High-Performance Low-Cost Anodes for Microbial Fuel Cells Using Real Food Wastewater. Chemical Engineering \& Technology, 40(12), 2243-2250.

Mohan, S., \& Chandrasekhar, K. (2011). Solid phase microbial fuel cell (SMFC) for harnessing bioelectricity from composite food waste fermentation: Influence of electrode assembly and buffering capacity. Bioresource Technology, 102(14), 7077-7085

Moharir, P. V., \& Tembhurkar, A. R. (2018). Comparative performance evaluation of novel polystyrene membrane with ultrex as Proton Exchange Membranes in Microbial Fuel Cell for bioelectricity production from food waste. Bioresource Technology, 266, 291-296.

Moharir, P. V., \& Tembhurkar, A. R. (2018). Effect of recirculation on bioelectricity generation using microbial fuel cell with food waste leachate as substrate. International Journal of Hydrogen Energy, 43(21), 10061-10069.

Noori, P., \& Najafpour Darzi, G. (2015). Enhanced power generation in annular single-chamber microbial fuel cell via optimization of electrode spacing using chocolate industry wastewater. Biotechnology and Applied Biochemistry, 63(3), 427-434.

Oliot, M., Galier, S., Roux de Balmann, H., \& Bergel, A. (2016). Ion transport in microbial fuel cells: Key roles, theory and critical review. Applied Energy, 183, 1682-1704.

Pant, D., Van Bogaert, G., Diels, L., \& Vanbroekhoven, K. (2010). A review of the substrates used in microbial fuel cells (MFCs) for sustainable energy production (Vol. 101). Bioresource Technology. 
Pariente, M. I. (16 de Julio de 2017). Problemática de las aguas residuales de la industria alimentaria. Obtenido de Aguasresiduales.info: https://www.aguasresiduales. info/revista/noticias/problematica-de-las-aguas-residuales-de-la-industria-alimentaria-jilSR

Parot, S., Delia, M., \& Bergel, A. (2008). Acetate to enhance electrochemical activity of biofilms from garden compost. 2737-2742. Electrochim.

Radeef, A. Y., \& Ismail, Z. Z. (2019). Polarization model of microbial fuel cell for treatment of actual potato chips processing wastewater associated with power generation. Journal of Electroanalytical Chemistry., 836, 176-181.

Rahman, A., Borhan, M. S., \& Rahman, S. (2017). Evaluation of microbial fuel cell (MFC) for bioelectricity generation and pollutants removal from sugar beet processing wastewater (SBPW). Water Science and Technology, 77(2), 387-397.

Restrepo, M. (2012). Producción más limpia en la industria alimentaria. Cleaner Production in Food Industry, 88-101.

Revelo, D., Hurtado, N., \& Ruiz, J. (28 de Junio de 2013). Celdas de Combustible Microbianas (CCMs): Un Reto para la Remoción de Materia Orgánica y la Generación de Energía Eléctrica. Información Tecnológica, 24(6), 17-28. doi: 10.4067/S0718-07642013000600004

Rezaei, F., Richard, T., Brennan, R., \& Logan, B. (2007). Substrate-Enhanced Microbial Fuel Cells for Improved Remote Power Generation from Sediment-Based Systems. Environmental Science \& Technology, 41(11), 4053-4058. doi:10.1021/es $070426 \mathrm{e}$

Seijas, A. (2010). Aguas residuales en la industria agroalimentaria. UCAB.

Serment, J., Lara, E., Becerril, K., Suárez, S., \& Ramírez, N. (2017). Detección y aislamiento de microorganismos exoelectrógenos a partir de lodos del río Lerma, Estado de México, México. Rev. Int. Contam. Ambie, 33(4), 617-628.

Solano, M. (2011). Impacto ambiental por aguas residuales y residuos sólidos en la calidad del agua de la parte media- alta de la microcuenca del río Damas y pro- 
puesta de manejo. Obtenido de https://www.aya.go.cr/centroDocumetacion/catalogoGeneral/Impacto\%20ambiental\%20por\%20aguas $\% 20$ residuales $\% 20 y \% 2$ Oresiduos $\% 20$ s\%C3\%B3lidos $\% 20$ en $\% 20$ la\%20calidad\%20del\%20agua.pdf

Song, R., Zhao, C., Jiang, L. A.-H., Zhang, J., \& Zhu, J. (2016). Bacteria-Affinity 3D Macroporous Graphene/MWCNTs/Fe3O4 Foams for High-Performance Microbial Fuel Cells. ACS Applied Materials \& Interfaces, 8(25), 16170-16177.

Sreelekshmy, B. R., Basheer, R., Savithri, S., lal, V., Elias, L., \& Shibli, S. M. (2020). Sustainable Electric Power Generation from Live Anaerobic Digestion of Sugar Industry Effluents Using Microbial Fuel Cells. Journal of Materials Chemistry A.

Tekerlekopoulou, A., Economou, C., Tatoulis, T., Akratos, C., \& Vayenas, D. (2020). Wastewater treatment and water reuse in the food industry. The Interaction of Food Industry and Environment, 245-280.

WWAP. (2015). Informe de las Naciones Unidas sobre el desarrollo de los recursos hídricos en el mundo 2015: Agua para un mundo sostenible. París.

WWAP. (2017). Informe de las Naciones Unidas sobre el desarrollo de los recursos hídricos en el mundo 2017: Aguas residuales, el recurso sin explotar. París.

Yan, D., Yang, X., \& Yuan, W. (2015). Electricity and H2 generation from hemicellulose by sequential fermentation and microbial fuel/electrolysis cell. Journal of Power Sources, 289, 26-33.

Yu, J., Park, Y., Kim, B., \& Lee, T. (2015). Power densities and microbial communities of brewery wastewater-fed microbial fuel cells according to the initial substrates. Bioprocess Biosyst Eng, 38, 85-92.

Zhao, Q., Yu, H., Zhang, W., Kabutey, F., Jiang, J., Zhang, Y., Wang, K., \& Ding, J. (2017). Microbial fuel cell with high content solid wastes as substrates: a review. Frontiers of Environmental Science \& Engineering, 11(2). 